\title{
Unprecedented Greenland melt
}

In recent years, the surface of the Greenland Ice Sheet (GrIS) has undergone substantial melt, contributing to sea level rise. Melt events are largely dominated by distinct episodes wherein vast swathes of Greenland's surface are rapidly lost, as observed in 2010 , 2012 and most recently 2019.

This latest melt episode must be analysed in the longer-term context of the modern instrumental era to better understand contemporary changes and improve future projections.

Marco Tedesco from the LamontDoherty Earth Observatory and

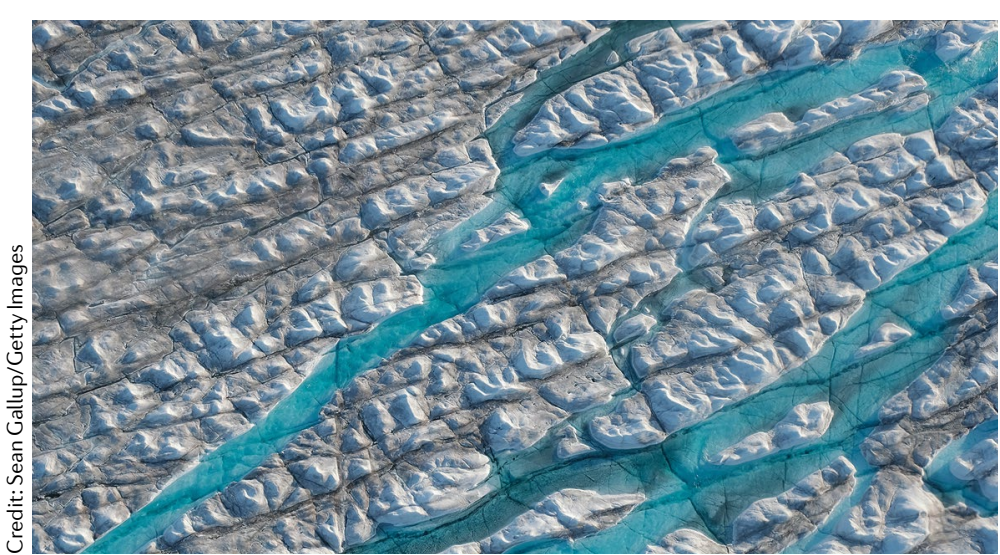

NASA Goddard Institute for Space Studies, USA and Xavier Fettweis from the University of Liège, Belgium, use a combination of observations, regional climate model output, reanalysis data and artificial neural networks to characterize the 2019 event. Melting during 2019 is related to positive surface temperatures, driven by exceptionally persistent anticyclonic conditions and corresponding advection of very warm air from the east (which also promoted severe heat wave conditions across Europe). Surface melt was therefore found to exceed the long-term mean for $\sim 82 \%$ of the days from June to August, resulting in $560 \mathrm{Gt}$ of meltwater runoff. Despite warmer temperatures, however, the runoff ranks second to 2012 , during which time $610 \mathrm{Gt}$ losses were observed. Yet, surface mass balance (that is, the net balance between ice gains from snowfall and ice loss through melt) was the lowest on record during 2019, with anomalies reaching $320 \mathrm{Gt}$, exceeding the 2012 melt season by $10 \mathrm{Gt}$ owing to differences in snow accumulation.

The contrasts between 2012 and 2019 demonstrate the importance of atmospheric conditions, specifically moisture and the spatiotemporal evolution of circulation patterns, in modulating melt responses and therefore future projections. With seemingly increased frequency and magnitude of melt events, however, it may not be too long until existing surface mass balance records are broken once more.

Graham Simpkins

ORIGINAL ARTICLE Tedesco, M. \& Fettweis, X. Unprecedented atmospheric conditions (1948-2019) drive the 2019 exceptional melting season over the Greenland ice sheet. The Cryosphere 14,1209-1223 (2020) 